\title{
Life cycle assessment of electric and conventional cars energy consumption and $\mathrm{CO}_{2}$ emissions
}

\author{
Ivan Evtimov ${ }^{1}$, Rosen Ivanov, ${ }^{1, *}$, Georgi Kadikyanov ${ }^{1}$, and Gergana Staneva ${ }^{1}$ \\ ${ }^{1}$ University of Ruse, Department of Engines and Vehicles, Bulgaria
}

\begin{abstract}
This paper presents an analysis concerning the effectiveness of electric traction in comparison with conventional cars. The Life Cycle Assessment method is used. It estimates the energy spent for the extraction of the raw materials/sources, manufacturing and transportation of the components and the vehicle, motion, maintenance and repair during exploitation period and the recycling process. The impact of the production technology of the electric energy, needed for charging the battery, is taken into account. The energy consumption and $\mathrm{CO}_{2}$ emissions for the life cycle of electric and conventional cars are presented on graphs. Examples for Bulgaria and EU countries are given. The exploitation conditions in which the electric car is more effective regarding $\mathrm{CO}_{2}$ equivalent emissions are shown. The main influence on the effectiveness of electric cars has the structure of the energy mix of the country where the electric car is produced and is used in exploitation.
\end{abstract}

\section{Introduction}

In view of decreasing the impact of vehicles on global warming in recent years, more and more electric cars replace the conventional ones. Following this trend, a lot of companies direct their efforts at producing cars with electric propulsion using Li-ion battery. An electric car at appropriate running conditions can be more effective than the conventional one in terms of environment safety. The general structure of an electric car is presented on Fig. 1. This kind of vehicles use the electric energy accumulated in the traction battery, which supplies the electric motor. Different kinds of batteries ( $\mathrm{Li}$-ion, $\mathrm{LiFePO}_{4}$ etc.) and electric motors (PMDC, BLDC, AC etc.) exist.

There are studies [1-4] of the effectiveness of electric car vs. conventional ones in terms of emissions of greenhouse gases adjusted to carbon dioxide equivalent $\left(\mathrm{CO}_{2}\right)$. Usually, this type of studies are done using the Life Cycle Assessment (LCA) method [5] and the comparison is made for the energy consumption and/or $\mathrm{CO}_{2}$ emissions. LCA is used to assess the environmental impact during all stages of vehicle life including extraction of raw materials and energy source, materials processing, vehicle manufacture, distribution (transport), use (motion) including maintenance and repair, and finally recycling or disposal [5]. The interest of researchers [1-4, 6-9], and our interest is focused mainly on the results for energy consumption and $\mathrm{CO}_{2}$ emissions, obtained through LCA.

In [1] different models of cars are studied. The main conclusion is that all the BEVs researched have lower $\mathrm{CO}_{2}$ emissions than ICE vehicles when the electricity comes from the European mix. The well-to-wheel $\mathrm{CO}_{2}$ emissions are reduced by approximately $50 \%$ as compared to a similar internal combustion engine vehicle. It is not clear what is the energy spent for battery production.

Study [2] calculates the energy inputs and $\mathrm{CO}_{2}$ equivalent emissions of a conventional gasoline vehicle, a hybrid vehicle, and a battery electric vehicle. The aim is to determine the lifecycle environmental costs of each vehicle type in conditions of California. The main purpose of the study is to examine the environmental impact of each vehicle type, taking into account lifecycle energy usage and both $\mathrm{CO}_{2}$ equivalents and air pollution emitted. The models are developed and the impact of a variety of factors, including carbon intensity of gasoline and electricity, varied electricity mixes, battery lifetime, and fuel economy is studied. The cost effectiveness for each vehicle type was also calculated.

Study [3] models the relative impact of new BEVs and ICEVs in the US for the year 2015, and it projects the economic and environmental impact of BEVs and ICEVs over the entire assumed twenty-year lifetime of a US passenger vehicle.

A lot of sources [6, 7, 9-16] contain particular data about the elements and processes included in LCA of cars, but some of them are fragmentary and contradictory, which does not permit appropriate use for comparative analysis.

The results from the above mentioned studies show that the average electric energy mix of the respective country has the main impact on $\mathrm{CO}_{2}$ emissions. A full comparative analysis, based on the LCA method and concerning used energy and generated $\mathrm{CO}_{2}$ emissions of electric and conventional cars in Bulgaria does not exist. The present paper is concerned with that problem. LCA of electric and conventional cars, based on data about the

\footnotetext{
* Corresponding author: rossen@uni-ruse.bg
} 
electric energy mix in some specific EU countries (like Norway, Poland and Bulgaria) and in EU-28, is made.

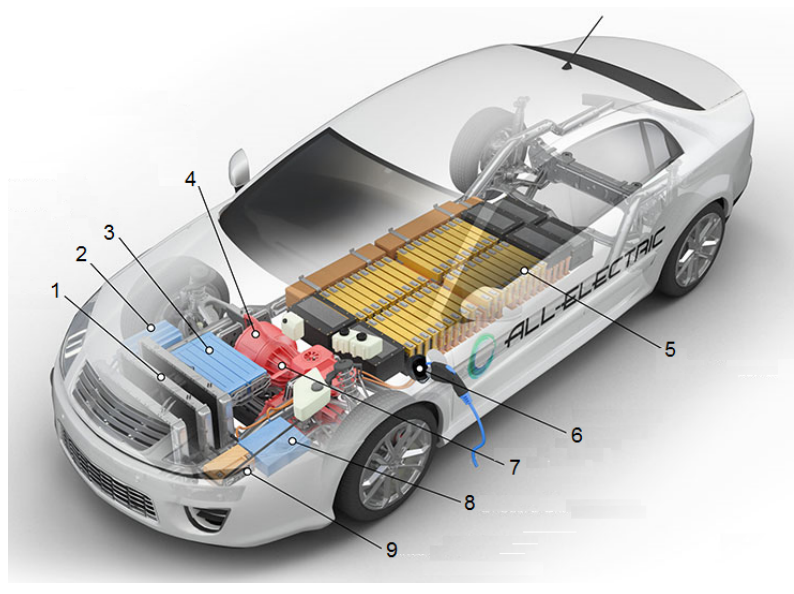

Fig. 1. Structure of an electric car:

1 - cooling system; 2 - DC/DC convertor;

3 - power electronics; 4 - electric motor; 5 - traction battery;

6 - charging contact; 7 - transmission; 8 - charging device;

9 - operational battery.

\section{Comparative Life Cycle assessment for the conventional and battery electric cars}

The generated emissions in $\mathrm{CO}_{2}$ equivalent for production of $1 \mathrm{kWh}$ electric energy depend on the electric energy mix for the respective country. In Europe, the larger part of electricity is produced by thermal power stations using coal (TPS), nuclear power stations (NPS) and stations using renewable energy sources (RES). In some countries like Holland, the main part of the electricity is produced using natural gas (NG). In Table 1 the electric energy mix for European counties (EU-28) is presented [10, 11, 17]. In the last row, similar information about Norway is given $[10,11]$. In some of the countries, the total percentage is not a full $100 \%$ because of using small local electric generators, which is not significant for the statistics.

During the production process, power stations' direct and indirect emissions are generated. The volume of that emission depends on the life cycle of the power station. For example, production of electricity from NPS and from RES has no direct emissions and this is the reason to use electricity produced in such stations for charging electric cars.

The summarized information for the countries of EU28 concerning the emissions of $\mathrm{CO}_{2}$ generated for the production of $1 \mathrm{kWh}$ electric energy is given in the Table $2[8,11]$. The whole life cycle of the used primary energy source is taken into account. In different countries, even with the same type of primary energy source, the volume of emissions may not be equal. Many factors impact these emissions (like needed energy for production and transport of the fuel, using the innovative technologies in production process etc.), but they will not be analyzed in this paper.

For a correct LCE of the electric and conventional cars all spent energy, including energy for production the primary energy source, for car and battery production, for using the car and finally for utilizing the old components, have to be considered.

Table 1. Electric energy production (mix) of the EU-28 countries and Norway $[10,11,17]$.

\begin{tabular}{|c|c|c|c|c|c|}
\hline \multirow{3}{*}{ Country } & \multicolumn{5}{|c|}{ Share of total production, $\%$} \\
\hline & \multirow{2}{*}{ 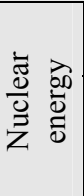 } & \multicolumn{3}{|c|}{$\begin{array}{l}\text { Thermal power } \\
\text { station }\end{array}$} & \multirow{2}{*}{ 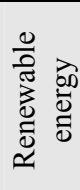 } \\
\hline & & 흥 $\frac{n}{0}$ & 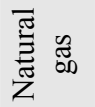 & 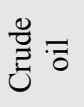 & \\
\hline Austria & 0,0 & 0,0 & 8,7 & 7,3 & 78,0 \\
\hline Belgium & 65,0 & 0,0 & 0,0 & 0,0 & 28,5 \\
\hline Bulgaria & 33,2 & 48,7 & 0,7 & 0,2 & 17,0 \\
\hline Croatia & 0,0 & 0,0 & 33,5 & 15,6 & 50,7 \\
\hline Cyprus & 0,0 & 0,0 & 0,0 & 0,0 & 97,4 \\
\hline Czech Republic & 24,2 & 58,6 & 0,7 & 0,7 & 14,9 \\
\hline Denmark & 0,0 & 0,0 & 26,4 & 48,7 & 22,5 \\
\hline Estonia & 0,0 & 75,6 & 0,0 & 0,0 & 23,2 \\
\hline Finland & 34,2 & 4,8 & 0,0 & 0,4 & 59,3 \\
\hline France & 82,5 & 0,0 & 0,0 & 0,8 & 15,7 \\
\hline Germany & 19,8 & 35,9 & 5,3 & 3,0 & 32,5 \\
\hline Greece & 0,0 & 67,0 & 0,1 & 0,7 & 31,2 \\
\hline Hungary & 36,7 & 13,6 & 12,2 & 7,6 & 29,0 \\
\hline Ireland & 0,0 & 39,8 & 5,6 & 0,0 & 51,3 \\
\hline Italy & 0,0 & 0,1 & 15,3 & 16,1 & 65,2 \\
\hline Latvia & 0,0 & 0,0 & 0,0 & 0,0 & 99,6 \\
\hline Lithuania & 0,0 & 1,3 & 0,0 & 4,8 & 92,5 \\
\hline Luxembourg & 0,0 & 0,0 & 0,0 & 0,0 & 76,9 \\
\hline Malta & 0,0 & 0,0 & 0,0 & 0,0 & 100,0 \\
\hline Netherlands & 2,2 & 0,0 & 82,0 & 4,3 & 10,1 \\
\hline Poland & 0,0 & 79,6 & 5,5 & 1,4 & 12,8 \\
\hline Portugal & 0,0 & 0,0 & 0,0 & 0,0 & 97,7 \\
\hline Romania & 11,3 & 17,7 & 33,0 & 15,6 & 22,3 \\
\hline Slovakia & 62,6 & 7,8 & 1,2 & 0,2 & 25,2 \\
\hline Slovenia & 43,0 & 25,4 & 0,1 & 0,0 & 30,2 \\
\hline Spain & 44,2 & 3,7 & 0,2 & 0,7 & 50,5 \\
\hline Sweden & 43,2 & 0,3 & 0,0 & 0,0 & 54,6 \\
\hline United Kingdom & 15,3 & 4,3 & 30,1 & 39,3 & 10,0 \\
\hline EU-28 & 28,9 & 18,9 & 14,0 & 9,8 & 26,7 \\
\hline Norway & 0,0 & 1,4 & 0,0 & 0,0 & 98,6 \\
\hline
\end{tabular}

In this study, the following values of the quantities and assumptions are used:

- equal mass of the battery electric (BEV) and conventional gasoline (CV) cars;

- energy consumption of the BEV - 0,210 kWh/km;

- fuel consumption of the CV - 7,6 1/100 km of gasoline;

- capacity of the battery of BEV - $40 \mathrm{kWh}$;

- equal range of the life cycle of the two types of vehicles - $290000 \mathrm{~km}$;

- energy for car production - $11900 \mathrm{kWh}$ [2];

- efficiency of NPS - 29,5\% [12];

- efficiency of TPS using coal - 26\% [13];

- efficiency of TPS using natural gas - 40\% [14];

- efficiency of water power station (WPS) - 60\% [15];

- efficiency of wind power station (WiPS) - 40\%;

- average efficiency of power stations using renewable energy sources $-50 \%$;

- losses for transport and distribution of the electricity $5 \%[1]$. 
Table 2. Emissions of $\mathrm{CO}_{2}$ in the production of electricity for EU-28 Member States [8] and Norway [11], g/kWh.

\begin{tabular}{|c|c|c|c|c|c|}
\hline Country & 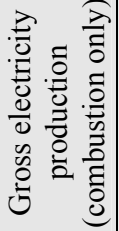 & 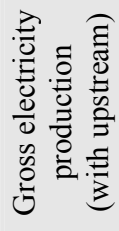 & 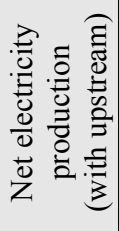 & 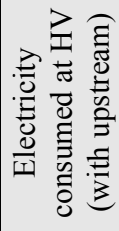 & 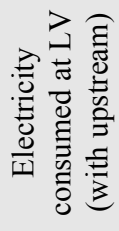 \\
\hline Austria & 133 & 151 & 156 & 322 & 334 \\
\hline Belgium & 188 & 224 & 233 & 261 & 267 \\
\hline Bulgaria & 507 & 532 & 585 & 618 & 669 \\
\hline Croatia & 231 & 273 & 282 & 487 & 524 \\
\hline Cyprus & 646 & 737 & 773 & 787 & 810 \\
\hline $\begin{array}{c}\text { Czech } \\
\text { Republic }\end{array}$ & 518 & 545 & 587 & 657 & 685 \\
\hline Denmark & 316 & 368 & 386 & 364 & 377 \\
\hline Estonia & 1020 & 1022 & 1152 & 878 & 944 \\
\hline Finland & 171 & 200 & 209 & 207 & 211 \\
\hline France & 66 & 88 & 92 & 100 & 105 \\
\hline Germany & 485 & 534 & 567 & 599 & 615 \\
\hline Greece & 655 & 695 & 755 & 732 & 767 \\
\hline Hungary & 310 & 340 & 368 & 383 & 407 \\
\hline Ireland & 459 & 533 & 555 & 588 & 617 \\
\hline Italy & 358 & 427 & 444 & 413 & 431 \\
\hline Latvia & 134 & 173 & 185 & 1110 & 1168 \\
\hline Lithuania & 204 & 246 & 262 & 370 & 390 \\
\hline Luxembourg & 236 & 288 & 283 & 508 & 513 \\
\hline Malta & 731 & 831 & 868 & 954 & 1032 \\
\hline Netherlands & 479 & 559 & 582 & 555 & 569 \\
\hline Poland & 770 & 847 & 929 & 937 & 980 \\
\hline Portugal & 295 & 346 & 355 & 372 & 400 \\
\hline Romania & 356 & 379 & 413 & 449 & 492 \\
\hline Slovakia & 173 & 199 & 211 & 412 & 420 \\
\hline Slovenia & 315 & 329 & 351 & 309 & 321 \\
\hline Spain & 248 & 295 & 305 & 321 & 341 \\
\hline Sweden & 16 & 24 & 25 & 45 & 47 \\
\hline $\begin{array}{c}\text { United } \\
\text { Kingdom }\end{array}$ & 469 & 555 & 584 & 593 & 623 \\
\hline EU-28 & 340 & 387 & 407 & 428 & 447 \\
\hline Norway & - & - & - & - & 17 \\
\hline
\end{tabular}

The fuel consumption of the $\mathrm{CV}$ is determined based on the specific energy and efficiency of its internal combustion engine, and with the assumption to have the same volume of energy as that one used for motion of the BEV [2]. In the values of efficiency of different power stations, the losses for extraction of the primary energy sources (coal, natural gas etc.) are taken into account.
The efficiency for fuel production is accepted to be $79,6 \%[6,7,16]$.

The performance of the BEV basically depends on the type of traction battery. The production technology of Lithium-ion battery for electric cars is not so cheap in comparison with traditional lead-acid battery.

The energy spent for the production, transport, recycling etc. of the most popular types of battery was calculated on the basis of data from [9] and is shown in Fig. 2. Our study about battery recycling confirms the popular opinion that this process is not economically effective because of high energy consumption and waste products presence. Probably in the future battery recycling will be oriented basically for ecological effect and observance of ecological law.

The results show that the life cycle of Li-ion battery needs about $420 \mathrm{kWh}$ per each kWh of battery capacity. For a middle size battery of $40 \mathrm{kWh}$ capacity, approximately $16800 \mathrm{kWh}$ energy will be used during the life cycle of the BEV, if only one battery is used during the life cycle of BEV (range of $290000 \mathrm{~km}$ ). The battery construction permits repair and change of elements. According to some authors [2] it is reasonable to make calculation for 1,5 batteries. In this case, the energy for the life cycle of battery will be one and half times more.

Taking into account the values of the energy spent for car production, battery life cycle and energy or fuel for passing a distance of $290000 \mathrm{~km}$, the needed energy for the life cycle of BEV or $\mathrm{CV}$ can be calculated. The obtained results for primary energy used in the life cycle of BEV, produced and driven in 4 countries, are presented in Fig. $3 a$. The energy mix and efficiency of the power station for different countries are used in the calculations.

Generally, the life cycle of the gasoline CV, produced and driven in Bulgaria, needs approximately $309750 \mathrm{kWh}$ of primary energy. About $86,5 \%$ of the life cycle energy is spent on motion. This percentage depends on the energy for car production in the respective country and the last one depends on the energy mix. The energy for motion/ driving changes insignificantly in different countries and basically depends on the losses in the fuel production process. Other stages of the life cycle of CV like production of vehicle and parts, their transportation etc. consume less energy $-13,5 \%$ of life cycle energy or approximately $42000 \mathrm{kWh}$.

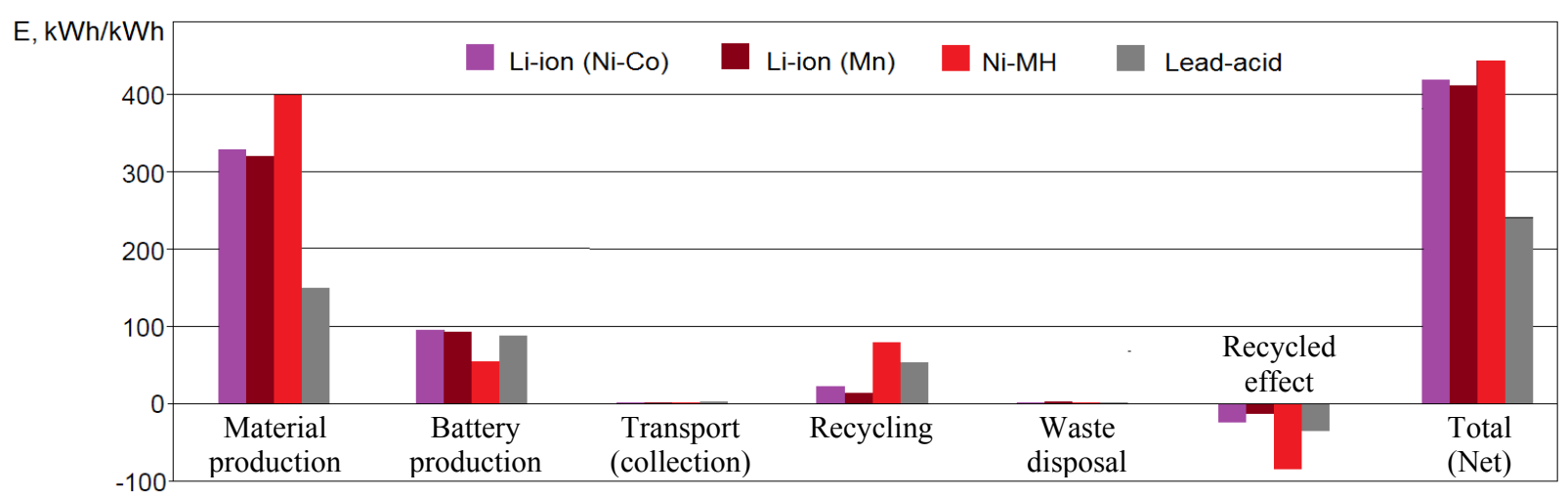

Fig. 2. Energy spent for production and recycling per $1 \mathrm{kWh}$ of capacity of the different battery types. 
The life cycle of BEV-1, produced and driven in Bulgaria, needs approximately $355210 \mathrm{kWh}$. In other words in these conditions electric cars need $15 \%$ more primary energy than $\mathrm{CV}$ (Fig. $3 a$ ). The largest part of the energy goes for charging the battery $-71,5 \%$ of life cycle energy. Production of the battery has significant influence - $16,7 \%$ on life cycle energy which is equal to $59290 \mathrm{kWh}$. The energy for the production of the vehicle and parts for repair, their transportation etc. is $11,8 \%$ or $42000 \mathrm{kWh}$ (value is the same like for $\mathrm{CV}$ ).

The life cycle of the BEV-2 produced with the average energy mix of EU-28 and driven in Europe needs 16\% less primary energy as compared to BEV-1.

Most effective in terms of the spent energy during its life cycle is BEV-3 produced and driven in Norway. The primary energy is two times less (49\%) than the energy spent for BEV-1, 42\% less than CV in Bulgaria and 38\% less than $\mathrm{CV}$ in Norway (it is not shown in Fig. $3 a$ ).

The worst scenario is the production and driving of BEV-4 in Poland - about 51\% more than BEV-3 (in Norway).

The emissions of $\mathrm{CO}_{2}$ generated during the life cycle of the vehicles in Fig. $3 a$ are calculated using data from Table 2 and are presented in Fig. $3 b$. The BEV-1 for its life cycle generates $59940 \quad \mathrm{~kg} \quad \mathrm{CO}_{2}$ emissions. Approximately the same are the emissions of $\mathrm{CV}$ in Bulgaria $-59750 \mathrm{~kg}$. However, priority must be given to BEV-1 because the emissions from the electric vehicle are generated where the electricity is not produced in big towns. The BEV-2 generates $31 \%$ less emissions $40050 \mathrm{~kg}$. BEV-3 generates the least $-1530 \mathrm{~kg}$, which is 39 times less than BEV-1 and 26 times less than BEV-2 and 59 times less than BEV-4. In comparison with $\mathrm{CV}$ in Norway, the BEV-3 has 34 times less emissions.

In Table 3 the spent primary energy and generated emissions of $\mathrm{CO}_{2}$ per $1 \mathrm{~km}$ distance are shown. An assumption is accepted - all vehicles consume equal secondary energy of $0,309 \mathrm{kWh} / \mathrm{km}$. This value includes energy consumption of the BEV, and the efficiency of the charging station and battery.

BEV-4 has the highest level of energy consumption and generated emissions. It is produced and driven in Poland, where $78,6 \%$ of the electricity is from thermal power stations using coal. The most effective one is BEV3 produced and driven in Norway, where the part of renewable energy is $98,6 \%$. The analysis of these results shows the most effective way to increase the effectiveness and to reduce the emissions of BEV - change the energy mix of the country by using more nuclear power stations and renewable energy sources. The process will also cause change of the emissions for the life cycle of BEV. This effect is illustrated in Fig. 4 for energy mix and $\mathrm{CO}_{2}$ emissions in Bulgaria - 0,669 kg/kWh (see Table 2).

For example, if the level of emissions decreases to $0,4 \mathrm{~kg} / \mathrm{kWh}$, for the life cycle of BEV $24126 \mathrm{~kg}$ of $\mathrm{CO}_{2}$ can be saved. On the contrary, if the energy mix is changed and the part of TPS using coal increases, as a result at emission level $0,9 \mathrm{~kg} / \mathrm{kWh}$, the generated emissions for the life cycle of the BEV will exceed the respective ones for the $\mathrm{CV}$ by about $20717 \mathrm{~kg}$.
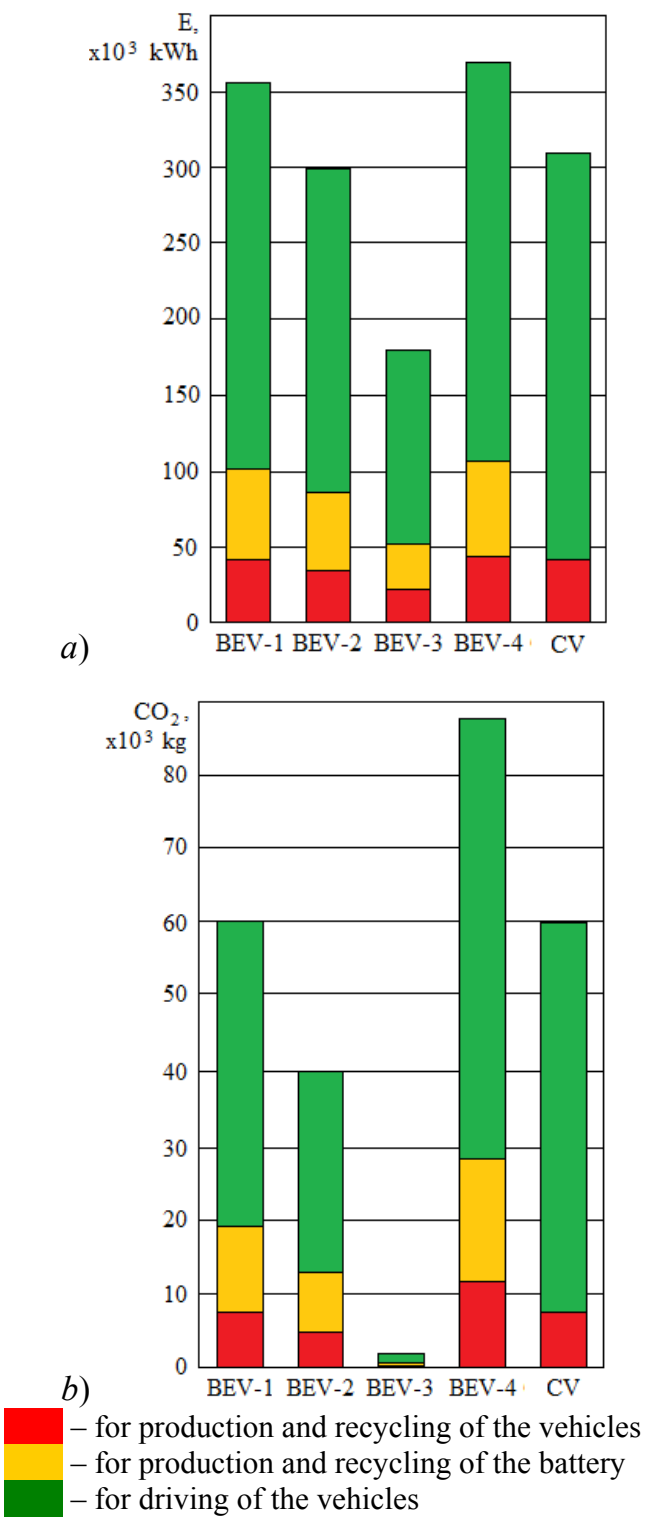

Fig. 3. Life cycle of primary energy (a) and life cycle of $\mathrm{CO}_{2}$ emission (b).

$\mathrm{BEV}-1$ - production and driving in Bulgaria;

BEV-2 - production and driving with data for EU-28;

BEV-3 - production and driving in Norway;

BEV-4 - production and driving in Poland.

Table 3. The needed primary energy and $\mathrm{CO}_{2}$ emissions per $1 \mathrm{~km}$ distance.

\begin{tabular}{|c|c|c|}
\hline Vehicle & $\begin{array}{c}\text { Primary energy, } \\
\mathrm{kWh} / \mathrm{km}\end{array}$ & $\begin{array}{c}\mathrm{CO}_{2}, \\
\mathrm{~g} / \mathrm{km}\end{array}$ \\
\hline BEV-1 & 1,156 & 207 \\
BEV-2 & 1,030 & 138 \\
BEV-3 & 0,620 & 5,28 \\
BEV-4 & 1,272 & 303 \\
\hline CV & 1,068 & 206 \\
\hline
\end{tabular}

The relation is well approximated with the following linear equation

$$
\mathrm{CO}_{2}=-89686 x+60000, \mathrm{~kg},
$$

where $x$ is level of the generated $\mathrm{CO}_{2}$ emissions, $\mathrm{kg} / \mathrm{kWh}$. 


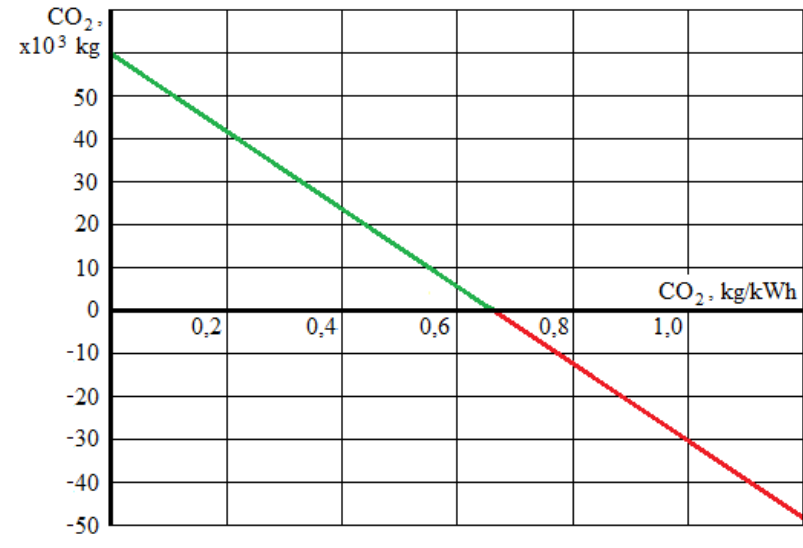

Fig. 4. Saved $\mathrm{CO}_{2}$ emissions for the life cycle of the BEV vs emissions generated for the production of $1 \mathrm{kWh}$ of electric energy.

\section{Conclusion}

On the basis of statistical data for the energy mix and generated $\mathrm{CO}_{2}$ emissions for different EU countries an LCE concerning the energy consumption and $\mathrm{CO}_{2}$ emissions of BEV and $\mathrm{CV}$ was done. The variants in the different countries were described. At conditions in Bulgaria (energy mix for year 2015 and level of emissions for the electricity production of $669 \mathrm{~kg} / \mathrm{kWh}$ ) the BEV-1 and the CV have practically equal emissions for their life cycle. The priority must be given to BEV-1 because the emissions related to the electric vehicle are generated where electricity is produced - not in big towns.

Use of RES for electricity production can reduce $\mathrm{CO}_{2}$ emissions for the life cycle of BEV by up to 40 times in comparison to $\mathrm{CV}$. A good example in this direction is Norway where $98,6 \%$ of energy is produced from RES, the life cycle energy of BEV is $40 \%$ less than the average one for EU-28 countries. The emissions are 26 times less than the average one for EU-28 countries. A negative example can be the life cycle of BEV in Poland. As a large part of electricity is produced in coal TPS the primary energy and level of the emissions are very high.

The LCE and the analysis of the results shows that the most effective way to increase the effectiveness and to reduce the emissions of $\mathrm{BEV}$ is changing the energy mix of the country by using more nuclear power stations and renewable energy sources.

The production technology of LI-ion battery is continuously developed, but it is still an obstacle for replacing conventional cars with battery electric vehicles. Battery recycling now is not an effective process and in the future ecological problems are possible.

\section{References}

1. D. Bakker, Battery electric vehicles. Performance, $\mathrm{CO}_{2}$ emissions, lifecycle costs and advanced battery technology development. Master thesis Sustainable Development, Energy and Resources, Copernicus institute University of Utrecht, 75 (2010)
2. Aguirre K., L. Eisenhardt, C. Lim, B. Nelson, A. Norring, P. Slowik, N.Tu, Lifecycle Analysis Comparison of a Battery Electric Vehicle and a Conventional Gasoline Vehicle. California Air Resources Board, 33 (2012)

3. J. Brennan, T. Barder, Battery electric vehicles vs. internal combustion engine vehicles. A United StatesBased Comprehensive Assessment, Arthur D. Little, 48 (2016)

4. I. Evtimov, R. Ivanov, G. Kadikyanov, A comparative analysis of the vehicles energy performance, BulTrans-2016, Sozopol (2016)

5. IS0 14040/44:2006, Environmental management Life cycle assessment.

6. I. Palou-Rivera, J. Han, M. Wang, Updates to petroleum refining and upstream emissions, Center for Transportation Research Argonne National Laboratory, CTR/Argonne, 12 (2011)

7. Petroleum diesel life cycle energy demand, available at:https://hub.globalccsinstitute.com/publications/bio fuels-policies-standards-and-technologies/petroleumdiesel-life-cycle-energy-demand

8. A. Moro, L. Lonza, Electricity carbon intensity in European Member States: Impacts on GHG emissions of electric vehicles. European Commission, Joint Research Centre (JRC), Italy, Transportation Research Part D (Elsevier, 2017).

9. K. Ishihara, N. Kihira, N. Terada, T. Iwahori, Environmental burdens of large lithium-ion batteries, Developed in a Japanese National Project, Central Research Institute of Electric Power Industry, Tokyo, Japan (2013)

10. R. Fischer, E. Elfgren, A. Toffolo, Energy supply potentials in the northern counties of Finland, Norway and Sweden towards sustainable Nordic electricity and heating sectors, Energy Engineering, Luleå University of Technology, Sweden, 31 (2018)

11. S. Skaalbones. Electricity disclosure 2015. https://www.nve.no/energy-market-andregulation/retail-market/electricity-disclosure-2015/

12. O. Eriksson, Nuclear power and resource efficiency A proposal for a revised primary energy factor, Department of Building, Energy and Environmental Engineering, Faculty of Engineering and Sustainable Development, University of Gävle (2017)

13. A. Scott, R. Wedmaier, The assessment and control of coal damage and loss, Project Number C3017 University of Queensland, www.acarp.com.au/abstracts.aspx?repId $=\mathrm{C} 3017$

14. Steam-gas power stations, Energy Review, 3 (2010)

15. Real world hydro power calculation, The Renewable Energy Website. http://www.reuk.co.uk/ wordpress/hydro/calculation-of-hydro-power/

16. M. Wang, Estimation of energy efficiencies of U.S. petroleum refineries, Center for Transportation Research, Argonne National Laboratory (2008).

17. Energy production, 2005 and 2015, available at: https://ec.europa.eu/eurostat/statisticsexplained/index.php?title=File:Energy_production,_2 005_and_2015_(million_tonnes_of_oil_equivalent)_ YBī7.png 